\title{
Locating the difference: A comparison of pedagogic strategies in high and low performing schools
}

\begin{abstract}
A number of research studies have suggested that specific pedagogic strategies can have a positive impact on learning, and in turn, have a positive impact on school performance, in particular for children being schooled in disadvantaged contexts. This analysis describes and measures how four of these pedagogic strategies identified in research - the pacing of a lesson, the sequence and coherence of a lesson, cognitive demand and the nature of feedback within a lesson - are displayed in higher and lower performing schools located in lower-income communities in the Western Cape. The analysis forms part of a broader research project, SPADE (Schools Performing Above Demographic Expectation), and is based on fifteen video-recorded Grade 3 numeracy lessons. The analysis suggests a relationship between specific pedagogic strategies and higher performance for individual learners and for schools. The analysis also identifies further effective pedagogic strategies in higher performing schools in lowerincome communities.
\end{abstract}

Keywords: pedagogy, numeracy, comparative research studies, teaching strategies, variation in learner and school achievement, primary education

Kaylianne Aploon-Zokufa, SPADE Project, University of Cape Town. Email address: iceboxk@gmail.com

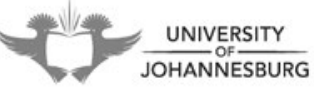




\section{Introduction}

Measuring specific features of classroom practice and creating a link between these features and school performance is crucial for two reasons. The first is that it enables a deeper understanding of differential performance in South African schools. The second reason concerns identifying pedagogic strategies that are related to better outcomes. If we can identify these strategies, we may find ways of optimising students' opportunity to learn, which is particularly important in schooling in poorer contexts. Small-scale studies on classroom practices in South Africa have provided much detail by describing the state of teaching and learning in classrooms. These studies however, have not been able to show the specific ways in which certain pedagogic strategies influence learner and school achievement (Hoadley, 2012). Many of these studies have also not been able to provide 'robust constructs for measuring classroom factors' (Hoadley, 2012:198). Further research which develops better measures of classroom factors and that provides broader understanding of how certain pedagogic strategies influence learner achievement, is crucial.

This paper aims to contribute to this research by showing through a small sample how measurement of particular dimensions of pedagogy can be related to student outcomes. By focusing on these dimensions of pedagogy within the light of the performance of the schools in the sample, the paper demonstrates and then compares the display of four features of pedagogy within the selected higher and lower performing schools. There are two questions this paper aims to address. The first is what are the kinds of pedagogic strategies that are available to learners in lowerincome communities and how are the kinds of strategies that are available spread across schools of higher and lower performance? The second question is related to the primary concern of the broader project within which this analysis is based: can the practice of specific pedagogic strategies account for higher school performance in lower-income communities? The findings of this paper suggest that there is variation in the pedagogic strategies that are available to learners who benefit from schools situated in lower-income communities, but the spread of these strategies are unevenly distributed. The paper also suggests that weak pedagogies are more common in lower performing schools than in the higher performing band of schools.

\section{A review of South African classroom-based studies in numeracy}

Compared to an extensive literature elsewhere (Anghileri, 2006; Stylianou, 2010; Fuson, 1992), the South African research base on the learning of numeracy is very limited. Nonetheless, a few classroom-based research studies have begun to describe the impact that specific features of classroom practice can have on learning outcomes (Hoadley, 2012). Amongst these, some studies have shown that providing feedback to learners, pacing and differentiated pacing, strong subject knowledge demonstrated by teachers and coverage of the curriculum are all specific features of classroom practice that optimise learning (Taylor, 2007; Reeves \& Muller, 2005; Carnoy \& Chisholm, 2011). In what follows, the author expands on research that connects these specific dimensions of classroom practice to better outcomes. 
Hoadley's (2007) study highlights the importance of teachers to making 'the evaluation criteria explicit for learners', a Bernsteinian conception of feedback. In her study, Hoadley uses the idea of framing to measure whether the evaluation criteria is made explicit or not explicit during Grade 3 numeracy lessons. Hoadley found a relationship between more explicit evaluative criteria (or feedback) in the classroom and students being able to solve problems in mathematically efficient ways. When framing is strong and predominantly controlled by the teacher, learner achievement was higher (Hoadley, 2007). Through the notion of evaluative criteria, Hoadley draws attention to the extent to which teachers make learners aware of the criteria being used to assess (formally and informally) the knowledge they are being exposed to in the lesson. This is an on-going process throughout the lesson period, where the teacher explicitly defines and explains the meaning of concepts as well as connections between concepts, draws the attention of all pupils to key ideas within the lesson content and provides a regulated space for questions and responses (Hoadley, 2007). Morais \& Pires (2002) found that making the evaluative criteria explicit on an on-going basis strongly correlated with learning difficult concepts successfully, specifically for learners from lower income communities. They note that:

considering the importance of clearly telling children what is expected of them, of identifying what is missing in their textual production, of clarifying the concepts, of leading them to make synthesis and broaden concepts and considering the importance attributed to language as a mediator of the development of higher mental processes, one understands the influence of making the evaluation criteria explicit (Morais \& Pires, 2002:9).

In another study, also located in Foundation Phase numeracy classrooms; Ensor, Hoadley, Jacklin, Kühne, Schmitt, Lombard, \& Van den Heuvel-Panhuizen (2009) used the term 'semantic density' when referring to the particular relationship between text and time within the context of mathematics lessons in a project called Count One Count All (COCA).

The notion of semantic density grasps simultaneously the twin concerns of specialization of text, and its distribution over time ... High semantic density is achieved via the distribution of specialized text across concentrated periods of time: levels of semantic density can be reduced by localizing pedagogic text and/ or expanding pedagogic time (2009:14).

The authors also found that,

while shifts from concrete to abstract modes of reasoning were evident in all classrooms ... this did not happen at the pace or at the depth that learners require in order to move on to more complicated arithmetic operations in the intermediate years (Ensor et al., 2009:26).

They assert that the combination of a low conceptual level of the pedagogic text and the low rate of transmission has severe implications for learners' understanding of number in the early years (Ensor et al., 2009). This valuable contribution enables us to think of pedagogic features such as sequence, pace and cognitive demand as relational. When this web of classroom features is organised over a lesson period in a relational manner, it can impact learning more than when these features are thought of and organised in isolation. It also highlights the crucial fact that when particular 
features of pedagogy are structured and ordered from the beginning of a lesson to the very end, its effects on learner achievement and eventual school performance are positive and more salient.

In a similar study, also focused on numeracy in the Foundation Phase, Venkat \& Naidoo (2012) highlight the relationship between tasks teachers use in the classroom to illustrate key ideas and teacher talk or verbal communication. Their focus came after noticing 'disconnections' (2012:22) within classroom talk/verbal communication from the teacher as well as disconnections in the activities the teacher provided for learners to do after and during verbal communications. This particular study draws our attention to the notion of coherence.

\section{Coherence refers not only to how different parts of a text fit together but also how sense or meaning relations are connected within and across parts of the text ... Coherent explanations are characterized by strong cohesive ties across individual messages of a text that produce continuity (Venkat \& Naidoo, 2012:22).}

The authors argue that a connection between teacher talk and text (in terms of written activities) builds bridges between what learners already know and what they are currently exposed to. Also in relation to coherence, Reeves \& Mc Auliffe (2012) found that some teachers in South Africa do not have the necessary knowledge and skills to put topics or sub-topics taught over a period of time or within a lesson together into a coherent sequence. They argue that,

for teachers to become autonomous and plan, enact and responsively adapt a year's curriculum as a coherent entity underpinned by internal disciplinary principles, they first need to recognize that mathematics is not simply a collection of isolated and unrelated topics and sub-topics (2012:29).

According to Reeves \& Mc Auliffe (2012), teaching topics within lessons and within grades that are coherent and that follows a specific logic greatly intensifies learning opportunities in classrooms. To do this however, teachers need to have a firm knowledge of the subject they are teaching. Having strong subject knowledge potentially enables teachers to create and teach coherent lessons, create connections for learners between the topics taught within and across lessons as well as make these connections explicitly available to learners during the lesson time through teacher talk and written activities. This offers learners the potential to build new knowledge upon previous knowledge which is crucial in subjects like mathematics (Reeves \& Mc Auliffe, 2012).

A number of studies have also shown that opportunity to learn (OTL), a conceptual tool that measures what learners are exposed to in teaching, is instrumental in measuring learning gains over time. Most of these studies however, have used OTL to measure the differences between the intended curriculum and the actual curriculum learners are exposed to. In a study which compared teaching and learning in Botswana and South Africa, Carnoy, Chisholm \& Chilisa (2012) defined opportunity to learn as the

curriculum content made available to students, the cognitive levels at which various topics or sub-topics are covered, and the amount of contact time devoted to teaching the subject area (2012: 44). 
OTL was conceptualised as operating at the three levels of the curriculum specified in literature; the intended, the implemented and the attained curriculum (Carnoy et al., 2012). Elsewhere, OTL has been defined as including features such as; content coverage (the content learners are exposed to); content exposure (the amount of time learners are exposed to particular topics in the curriculum) and curricular pacing (coverage over time) (Reeves \& Mc Auliffe, 2012). The comparative study by Carnoy et al. (2012) describes one aspect of OTL as the level of cognitive demand at which teachers are pitching mathematics content to learners. The study found that learner achievement is directly related to:

teachers' knowledge of the mathematics they are supposed to be teaching, the quality of their mathematics teaching, which includes the level at which they teach the subject matter, and their coverage of the curriculum on which [our] learner tests were based (Carnoy et al., 2012:151).

These authors argue that the findings from their study show a positive correlation between teachers' pedagogy and learner achievement in both Botswana and South Africa. The study also suggests that specific pedagogic strategies such as the level of cognitive demand, at which content is taught, could potentially influence learning more positively. The authors conclude that a range of factors account for the differential performance in mathematics between the specific regions of Botswana and South Africa within which this study was located. Amongst these, the mathematical content knowledge of teachers in the region and their capacity to teach mathematics stand out as crucial features when considering ways in which to improve the mathematics achievement levels in both regions (Carnoy et al., 2012).

The work of Taylor, Muller \& Vinjevold (2003) also offers arguments around the relationship between cognitive demand and achievement. They argue that the establishment of low levels of cognitive demand reinforces the effects of poor planning as well as pacing and together these ensure that learners are deprived of crucial, valuable opportunities to learn the intended curriculum and its accompanying knowledge and skills. Once again, the authors suggest that it is a range of classroom features organised over a lesson period (i.e. dimensions of pedagogy considered in a relational way) that potentially impact learning. This is opposed to identifying single pedagogic factors, or thinking of classroom features in isolation.

The various research studies referred to above speak to specific factors of classroom teaching and learning or pedagogic strategies used by teachers in different regions. Findings indicate that these factors can possibly explain the performance of individual learners and possibly, the performance of schools. These studies implicitly and explicitly suggest a relationship between certain kinds of pedagogy, learner and school achievement. When looked at together, as a body of knowledge on teaching and learning, research on pedagogy has provided strong evidence that pedagogic features such as cognitive demand, explicit evaluative criteria, pacing and teaching coherent lessons within and across grades, have a positive impact on learning and learner results. Drawing on this body of literature, this paper further explores the links between pedagogy and performance. 


\section{Sample}

South African schools have been criticised for poor performance and poor management. Teachers, often those teaching in lower-income communities, have been described as having low levels of subject knowledge, low levels of professionalism and ineffective classroom practices (Carnoy et al., 2012; Taylor, 2008). This paper reports on a specific analysis within the SPADE project. The broader project is particularly concerned with better performing schools in poorer contexts, thus presenting a more differential picture of schools in these contexts than exists in the public imagination. My analysis measures differences and similarities between fifteen Grade 3 numeracy lessons taught by fifteen teachers within six of the SPADE schools. Whilst differences and similarities between the lessons were measured, this paper focuses on the differences. More significantly, it reports on the pedagogic strategies within these numeracy lessons that are associated with higher or lower school performance.

The SPADE project identified and selected fourteen schools situated in lowerincome communities within the Western Cape; nine of these schools have been performing above demographic expectation over a significant period of time. School performance was measured over four cycles of Western Cape Education Department (WCED) Grade 3 numeracy and literacy systemic tests (2004-2008). The fourteen schools were organised into five sets and each set represented schools in similar communities with comparative characteristics. Within each set however, there was one school that was performing below average and in line with demographic expectation. Schools that were formerly controlled by the Department of Education and Training (DET - which governed schools for 'black' learners) and schools that were formerly controlled by the House of Representatives (HOR - schools for 'coloured' learners) were purposefully grouped into the same sets. The schools within these sets thus share similar historical and current demographic profiles of learners and school communities. The grouping of schools in these sets allows for an added dimension of comparability between performance of former DET and former HOR schools. The overarching question that the project aimed to answer was: 'How can we account for poor schools performing above expectations given their demographic location?" Research was conducted in these fourteen schools in 2012 and mixed research methods were utilised to address the question posed by the project. One of the methods used during the data collection phase of the project was classroom observations. Grade 3 teachers within the SPADE schools were observed and video-recorded teaching one home language lesson, one first additional language lesson and one numeracy lesson. These lesson observations provide valuable data for investigating pedagogic strategies within the SPADE schools, which provide opportunities for us to analyse the features of lessons within classrooms that potentially impact on school performance. The video-recorded numeracy lessons were the main data selected and used for this analysis.

As stated above, schools in the sample were distinguished in terms of higher or lower performing schools and in terms of former HOR or former DET schools. This analysis initially only focused on comparing pedagogic strategies between teachers in 
higher and lower performing schools. However, after this initial analysis the author also found significant similarities and differences between teachers in former HOR and former DET schools. For this reason, this analysis is broadened to looking at the pedagogy of the schools in the selected sample in terms of former HOR and former DET schools as well. The analysis is divided into two parts, Analyses A and Analysis B. For analysis A, two of the sets of schools within the SPADE project were selected, one set consists of three former HOR schools, two of these schools are higher performing schools and one is a lower performing school. In contrast, the other set has three schools that are former DET schools, two of these schools are higher performing schools and one is a lower performing former DET school. The table below provides a summary of the schools within the SPADE project that have been used in the data set for this analysis.

Table 1: Summary of data set used for analysis

\begin{tabular}{|l|l|l|l|}
\hline $\begin{array}{c}\text { School } \\
\text { Code }\end{array}$ & \multicolumn{1}{|c|}{$\begin{array}{c}\text { Former } \\
\text { HOR/DET }\end{array}$} & WCED Performance (2004-2008) & \multicolumn{1}{|c|}{$\begin{array}{c}\text { Number of teachers at } \\
\text { school }\end{array}$} \\
\hline School 7 & HOR & Above Demographic Average & 3 teachers \\
\hline School 6 & HOR & Above Demographic Average & $\begin{array}{l}\text { 2 teachers (1 teacher not part } \\
\text { of analysis) }\end{array}$ \\
\hline School D & HOR & Below Average & 2 teachers \\
\hline School 8 & DET & Above Demographic Average & 3 teachers \\
\hline School 3 & DET & Above Demographic Average & 4 teachers \\
\hline School E & DET & Below Average & $\begin{array}{l}\text { 3 teachers (1 teacher not part } \\
\text { of analysis) }\end{array}$ \\
\hline
\end{tabular}

\section{Method}

Two separate analyses on the selected data set are performed. As mentioned before, the data set consisted of fifteen video-recorded numeracy lessons. Each of the fifteen lessons is transcribed and the transcriptions is described according to the main concept taught and, the total time spent on the lesson. The author then generated a more detailed description of the content taught, the examples used by the teacher, the instructions given and the corrections made during the lesson time. These detailed descriptions were then condensed into lesson overviews such as the two brief examples below:

\section{Case 1 (Former HOR set-Higher performing school)}

Teacher 6.2 at School 6 used 1 hour 12 minutes to teach a numeracy lesson. Place value was identified as the main concept taught in this lesson, because the teacher spent most of the lesson time on this concept. There were 11 different segments in the entire lesson. Each lesson segment introduced a different topic. This teacher covered Multiplication, Place Value, Rounding off to the nearest 10, Halving, Fractions, Time, Shapes and Counting during this lesson time. 


\section{Case 2 (Former DET set-Higher performing school)}

Teacher 3.3 at School 3 used 2 hours 15 minutes to teach a numeracy lesson. Number ordering was identified as the main concept taught in this lesson, because the teacher spent most of the lesson time on this concept. There were five segments in this lesson. Each lesson segment introduced a different topic. This teacher covered Place Value, Counting, Context Independent Sums, Word Problems and Number Ordering during this lesson time.

After this initial description and analysis of numeracy lessons, general similarities and differences between the former HOR schools and the former DET schools were found. The author also found that the pedagogic features of pacing, lesson sequencing and coherence, cognitive demand and nature of feedback stood out in these lessons and potentially contributed to them being vastly different from each other, both within and across schools. After analysing the general differences between the former HOR and the former DET schools, each lesson was coded on a scale and pedagogies were characterised as strong, moderate or weak, based on the nature of pacing, sequence and coherence, cognitive demand and nature of feedback displayed in the lesson. These codes were then tabulated to determine the variety and spread of different pedagogic strategies across the schools in the sample. This was done to assess the relationship between pedagogy and performance.

In what follows, the findings from the two analyses conducted are provided and the spread of pedagogies across the schools are discussed. In analysis A, the author focuses on the general differences between the two sets of schools, the one set being former HOR schools and the other set being former DET schools. The examples demonstrating specific pedagogic features as identified in some of the schools in the sample are extreme cases of the way these features were represented in the schools. These examples are the focus of analysis $B$. These examples serve as exemplary texts of features, evident in the full set of schools. The codes derived in the discussion of the paper are based on the entire group, all fifteen teachers within both sets.

\section{Analyses A}

The first analysis highlights general differences between the two sets selected. These differences confirm some of the things we know about teaching and learning in South African primary schools (outlined above) and they show differences across types of schools, specifically former HOR and former DET schools. The main differences observed in lessons across the two sets related to the following features. Pace measured by how much time was spent on verbal and written tasks within lessons; Instructions given by teachers - measured by the nature and relationship between teacher talk and learner talk (Ensor et al., 2009) within lessons; and Classroom interaction - this referred to the 'relationship between whole group teaching and individual efforts by learners' (Ensor et al., 2009:7). The nature of these differences is described in the table below: 
Table 2: General differences between DET set and HOR set in the sample

\begin{tabular}{|l|l|l|}
\hline \multicolumn{1}{|c|}{ Feature of lesson } & \multicolumn{1}{|c|}{ Former DET set } & \multicolumn{1}{c|}{ Former HOR set } \\
\hline Pace & $\begin{array}{l}\text { Slower pace of learning. } \\
\text { Excessive time spent on certain } \\
\text { segments of a lesson. }\end{array}$ & Faster pace of learning. \\
\hline $\begin{array}{l}\text { Instructions given by } \\
\text { teacher }\end{array}$ & $\begin{array}{l}\text { The same instruction is } \\
\text { given up to four times by the } \\
\text { teacher with no evaluation of } \\
\text { whether learners understood } \\
\text { the instructions when it was } \\
\text { given the first time. Exercises } \\
\text { in textbooks and workbooks } \\
\text { are also read by the entire class } \\
\text { together with the teacher (word } \\
\text { for word) before the class starts } \\
\text { doing the exercises. }\end{array}$ & $\begin{array}{l}\text { Teacher gives an instruction } \\
\text { once. Upon indication that } \\
\text { some learners in the class do } \\
\text { not understand the instruction, } \\
\text { the teacher might give the same } \\
\text { instruction one or two more } \\
\text { times, but never more than this. } \\
\text { Learners read through exercises } \\
\text { in textbooks/workbooks on their } \\
\text { own when they do the exercises. }\end{array}$ \\
\hline $\begin{array}{l}\text { When practicing numeracy with } \\
\text { the class, the teacher interacts } \\
\text { with the class predominantly } \\
\text { as a group and answers to } \\
\text { problems are generally given by } \\
\text { the class through 'chorusing' as } \\
\text { opposed to individual learners } \\
\text { answering. }\end{array}$ & $\begin{array}{l}\text { When practicing numeracy with } \\
\text { the class, the teacher interacts } \\
\text { with the class as a group; but } \\
\text { answers are not given in the form } \\
\text { of chorusing. The teacher elicits } \\
\text { answers from individual learners. } \\
\text { Individual learners stand in for } \\
\text { the class and the answers to } \\
\text { problems are thus made public. }\end{array}$ \\
\hline
\end{tabular}

These are the dominant features of classroom practice within the two sets analysed and they constitute the main differences between numeracy lessons in former DET and former HOR schools. Upon reading the literature, these features have consequences for student learning. When pacing is slow in a classroom, opportunities to learn are lost by learners in the class who might grasp concepts faster if they were taught at a faster pace. Slow pace is also detrimental to coverage of the curriculum (Hoadley, 2012). Elsewhere, Taylor, Muller \& Vinjevold (2003:78) also note that,

pacing is strongly related to cognitive demand. If pacing is too weak, and the class falls behind the intended curriculum, the appropriate level of cognitive demand will suffer.

If learners do not cover the curriculum in one grade, they are not prepared for the work they will be exposed to in the next grade, particularly in subjects like mathematics that have been identified as having a vertical knowledge structure (Muller, 2006). Hoadley (2012) argues that for learners who come from lower-income households where less academic support is given at home, the school becomes the primary site of learning.

Time wastage and slow pacing in poor schools is thus even more problematic given that the amount of time allocated to the task of enhancing these children's educational outcomes is already too little (2012:193). 
There are also substantial differences between the ways in which the teachers in the two sets give instructions. In essence, reading instructions for understanding and completing a task in the classroom is a skill that enable learners to progress in school. When teachers guide learners through exercises (word for word), the skill to read and understand exercises/tasks/tests on their own is not gained and an opportunity to learn is lost. Learners have a greater advantage when they do this on their own and are stretched to the point of listening to an instruction when it is given the first time, understanding it and applying it to the task. With practice, this can become a skill. In the same way, learning is stunted and individual learners lose valuable opportunities to learn when the class 'choruses' answers; rather than individual learners having opportunities to respond to questions and the class being exposed to the exchange between teacher and learner. The second analysis focuses on an assessment of differences between pedagogic strategies within the two sets.

\section{Analysis B}

The second analysis focuses on the different pedagogic features which stood out in the observed lessons, within and across schools. This section of the analysis looks more closely at pedagogic features such as pace, sequence and coherence, cognitive demand as well as nature of feedback. For each of these features, an example of strong and weak pedagogy is provided as demonstrated in these lessons to show how these features were identified within the numeracy lessons.

\section{Pace}

This refers to the particular relationship between the topics covered in a lesson (the text) and the time taken to cover this topic. Coverage of topics included the time spent on verbal instructions and responses as well as written work related to the topic. Pedagogies were identified as strong if the relationship between text and time was appropriate for the topic at hand. Pedagogies were identified as weak when teachers spent an inappropriate or excessive amount of time on one topic or covered a few topics over a long period. Strong pedagogies created an appropriate pace for the topics in the lesson across the lesson time. The following example indicates how pacing was manifested in weak and strong pedagogies. 


\section{School 7, Teacher 7.2}

Content/Topics covered: Four division problems and two word problems. 20 minutes

\section{Brief Lesson Description}

Teacher monitored the class, provided individual assistance where learners were struggling and marked the work of some learners who were done with their exercises. Time was appropriately allocated for the number of tasks given.

\section{School E, Teacher E.1}

Content/Topics covered: Ordering Numbers and Objects

\section{8 minutes}

\section{Brief Lesson Description}

Teacher asked five learners to come to the front and the class had to indicate which learner stood first, second, third, fourth and fifth. After this, the teacher drew five fruit on the board and learners had to, once again, indicate which fruit is first, second, third, fourth and fifth.

The lesson taught by teacher 7.2 indicated strong pacing, because there was an appropriate relationship between the manner in which the texts and activities in this segment of the lesson were spread across the time of the segment. Weak pacing was demonstrated by teacher E.1, because the teacher took 18 minutes to teach the concept of ordinal numbers through two very simple representations.

\section{Sequence and Coherence}

Following Venkat \& Naidoo (2012), the sequencing and coherence of a lesson refers to the extent to which the ordering of knowledge reveals a logic, amplifies meaning or makes sense. It also refers to the extent to which activities or written tasks that follow verbal communications from the teacher are related to those verbal communications. If there is a strong link for learners between verbal communications and written work in lessons then sequencing in a lesson is strong, if the link between the two are weak then the sequencing and coherence of the lesson is considered to be weak. Strong pedagogies were described as having coherent lessons with a defined sequence; weak pedagogies were described as not having a defined sequence and as not being coherent. An example of a coherent lesson with clearly defined sequencing was identified in the lesson by teacher 7.3 at School 7. An example of an unclear and weakly defined lesson sequence was identified in a lesson from teacher 8.2 at School 8. 


\section{School 7, Teacher 7.3}

\section{Content/Topics covered: Fractions}

\section{5 minutes}

\section{Brief Lesson Description}

Teacher started by representing fractions through circles, squares and rectangles. Learners had to colour different parts of the shapes in and then write the fraction name represented by the part of the shape that was coloured in. Then the learners practiced problems on fractions, such as colouring in different parts of fractions and naming the coloured proportion in fraction parts. The teacher then proceeded by representing fractions through number lines, learners identified the fractions, wrote them down and practiced more problems on fractions. This time they practiced representing fractions through number lines. The learners continued doing these types of problems on fractions throughout the lesson.

\section{School 8, Teacher 8.2}

Content/Topics covered: Context Independent Problems/Word Problems

\section{4 minutes}

\section{Brief Lesson Description}

For the first fifteen minutes of the lesson, the teacher wrote four problems, covering all four basic operations, on the board and explained what happens to the result of the problem if you multiply, divide, subtract or add the digits in these problems. For the next 19 minutes the teacher wrote two word problems on the board, learners read the two word problems and then proceeded to do them in their books. The teacher then added six more context independent problems for the learners to do on the board.

The lesson taught by teacher 7.3 was identified as having a clearly defined sequence and each part of the lesson segment provided opportunities for learners to amplify their understanding of fractions. The sequence of the lesson segment taught by teacher 8.2 was not clearly defined; the teacher placed random problems together, explained how to do some of the problems and instructed learners to do them. This was defined as a weak pedagogic strategy.

\section{Cognitive demand}

This refers to the cognitive level at which teachers were working with the learners in their classrooms. Some topics in numeracy are more difficult to work with than others, thus the topics teachers taught were taken into consideration to measure cognitive demand, the cognitive level at which they were working with the learners and the number range they were working in were also taken into account. Consideration was also given to the topics that had to be covered by teachers according to the CAPS curriculum at the time of data collection in classrooms, and the curriculum was also 
used as an indicator of cognitive level. For this feature, the topics taught and number ranges of two teachers are tabulated to illustrate a difference in cognitive demand in the two observed lessons. This comparison is shown below:

\begin{tabular}{|c|c|}
\hline $\begin{array}{c}\text { Strong Cognitive Demand/ School 7, } \\
\text { Teacher } 7.3\end{array}$ & $\begin{array}{c}\text { Weak Cognitive Demand/ School E, } \\
\text { Teacher E.1 }\end{array}$ \\
\hline $\begin{array}{l}\text { Counting ( } 2-220 \text { in } 2 \text { f forward and backward; } \\
3-330 \text { in } 35 \text { forward and backward; } 400-500 \\
\text { in } 20 \text { s forward and backward; } 300-800 \text { in } \\
505 ; 100-1000 \text { in } 100 \text { s) } \\
\text { Number Recognition (any } 3 \text { digit number } \\
\text { chosen by learners) } \\
\text { Addition (add } 10 \text { to the } 3 \text { digit number chosen } \\
\text { above) } \\
\text { Subtraction (subtract } 10 \text { from new number } \\
\text { above) } \\
\text { Round off to the nearest } 10 \text { (round new } \\
\text { number off to the nearest } 10 \text { ) } \\
\text { Fractions } \\
\text { Word problems (10 } \div 2 ; 23 \div 3 \text { ) } \\
\text { Fractions } \\
\text { Word problems ( } 34 \div 3 \text { ) } \\
\text { Long Division ( } 34 \div 3 \text { ) } \\
\text { Fractions } \\
\text { Measurement(Maximum/Minimum } \\
\text { temperatures) } \\
\text { Fractions } \\
\text { (Lesson time: } 1 \text { hour, } 42 \text { minutes) }\end{array}$ & $\begin{array}{l}\text { Context free calculations }(13+1 ; 17+5 ; 30-8 \text {; } \\
24-4 ; 12+12 ; 30-6) \\
\text { Counting }(3-42 \text { in } 3 \mathrm{~s}) \\
\text { Division }(21 \div 3) \\
\text { Counting }(4-60 \text { in } 4 \mathrm{~s}) \\
\text { Division }(28 \div 4) \\
\text { Counting ( } 2 \mathrm{~s} ; 4 \mathrm{~s} ; 10 \mathrm{~s}) \\
\text { Number Ordering }\left(1^{\text {st }}, 2^{\text {nd }}, 3^{\text {rd }}, 4^{\text {th }}, 5^{\text {th }}\right) \\
\text { Number Ordering }\left(1^{\text {st }}, 2^{\text {nd }}, 3^{\text {rd }}, 4^{\text {th }}, 5^{\text {th }}\right) \\
\text { Number Ordering }\left(1^{\text {st }}, 2^{\text {nd }}, 3^{\text {rd }}, 4^{\text {th }}, 5^{\text {th }}\right) \\
\text { Patterns (Addition) } \\
\text { (Lesson time: } 1 \text { hour, } 31 \text { minutes) }\end{array}$ \\
\hline
\end{tabular}

There are a few differences that emerge from this contrast in relation to cognitive demand. The first difference is the number range the two teachers were working with. Teacher 7.3 worked within a number range that included three digit numbers whilst teacher E.1 worked within a range that was limited to one and two digit numbers. The three digit number range is prescribed and compulsory in Grade 3 for numeracy. The second difference is the range of topics covered in the lesson by the two teachers. Teacher 7.3 covered a wider variety of topics whereas teacher E.1 covered fewer topics. The last difference refers to how counting was practiced in the two classes. The learners in teacher 7.3's class counted backward and forward. The learners in teacher E.1's class only counted forward.

\section{Nature of Feedback}

For this feature, three dimensions were focused on. The first dimension was whether teachers made the evaluation criteria for different aspects of the lesson explicit/ not explicit. The second dimension was whether evaluation criteria were made 
explicit publicly or privately. Publicly refers to when the teacher made the evaluation criteria explicit for the entire class to benefit from it, and privately refers to when the evaluation criteria was made for the benefit of only individual learners. The last dimension referred to the fluency with which teachers taught the numerical principles and the fluency with which they were able to continue with a lesson, after some kind of disruption occurred during the lesson. This was noted especially when learners were not able to provide the correct answer to a particular question or when no learner responded to a question being asked. Strong pedagogies were identified as those where the teacher demonstrated fluency, and was able to move on with the lesson without struggle after lesson disruptions. Strong pedagogies were also identified as those where the evaluation criteria was made explicit to the entire class. Weak pedagogies were identified as those that lack fluency and where criteria were either not made explicit or made explicit only to individual learners. The two contrasting examples show the manifestation of this pedagogic strategy.

\section{School 7, Teacher 7.2}

Content/Topics covered: Doubling

1 minute

\section{Brief Lesson Description}

Teacher asked her class to double 97. Individual learners raised their hands and the teacher then asked individual learners what their answers were. After each incorrect answer, the teacher said no and moved on to the next learner who had a hand raised. The teacher asked all the learners who had raised their hands what their answers were and after each one answered, the class and the teacher agreed that the answer was 194. The teacher then asked: How did we get that answer? The teacher and learners replied to this: We doubled 90 and we doubled 7, then we added the answers.

\section{School E, Teacher E.1}

Content/Topics covered: Division

\section{1 minute}

\section{Brief Lesson Description}

Teacher asked learners to divide 28 by 4 . Some learners in the class responded by saying that the answer was seven. The teacher did not respond to this answer at all, instead she started singing, after which she showed confusion about whether she asked $28 \div 4$ or $27 \div 4$. The teacher left the question at that, the answer was incomplete and the teacher moved on to another segment of the lesson.

The first example shows that in this lesson, the teacher made the evaluation criteria explicit for the learners by indicating when answers were wrong and stating the correct answer with the class. She also made a method for producing the answer 
available to the entire class. The second example, however, was a clear indication of the evaluation criteria not being made explicit to learners.

A lack of fluency was identified when a teacher relayed incorrect numerical rules or when a teacher was unable to recognise or deal seamlessly with incorrect answers from learners. In other words, the teacher displayed a lack of fluency in the mathematics and a lack of fluency in teaching. An illustrative example of this lack of fluency is seen in a segment of a lesson taught by teacher E.2. The teacher held up a card with the problem $13_{-}=8$ on it and showed this to the class. She then explained that to do this type of problem the learners had to swap the operation; from addition to subtraction and vice versa. The teacher proceeded to write the problem on the board as it was written on the card and swapped the operation from subtraction to addition, but kept the numbers in the same place. The problem now read $13^{+_{+}}=8$. Then the teacher asked the class what the answer was, and a learner answered 5 . The teacher said no. Another learner answered 21 to which the teacher said yes, this was the right answer. The teacher then wrote $21-13=$ _ on the board and the learners say the answer to this is 8 . At this point some learners in the class say the answer is 7 . The class then has a brief argument about whether the answer is 7 or 8 . The teacher does not respond to the argument, but simply tells learners to start counting in three's again. This segment of the teachers' lesson was filled with confusion from both the teacher and the learners. However, what is clear is that the numerical rule taught by the teacher, that of swapping the operation from subtraction to addition without changing the position of the numbers produced the wrong answer to the problem on the card. The 'rule' clearly did not enable the learners to answer $13{ }_{-}=8$ correctly. The teacher herself demonstrated a lack of understanding of the 'rule' she was trying to teach, which was to show that $13+_{-}=8$ can be answered by asking $13-8=$. This teacher clearly demonstrated a lack of fluency with the mathematics she was teaching.

\section{Discussion}

After identifying these pedagogic features within the lessons from the two sets, these features are used to code the pedagogic strategies of all the teachers in the six schools. This was done to be able to rate the pedagogy of each teacher on a scale of strong, moderate or weak. Strong pedagogies were identified as those that demonstrated strong pacing, coherent lesson sequencing, appropriate levels of cognitive demand, explicit evaluation criteria made publicly, and fluency in mathematics and teaching. Weak pedagogies were identified as those that showed weak pacing, lack of coherently sequenced lessons, inappropriate levels of cognitive demand, lack of explicit evaluation criteria, and lack of fluency in mathematics and teaching. Moderate pedagogies were identified as those that fell somewhere between strong and weak pedagogies i.e. they demonstrated some strong pedagogic features and some weak pedagogic features. The pedagogies of the teachers within each set were coded in the following way: 
Table 3: Coding of pedagogies for HOR and DET set

\begin{tabular}{|l|l|}
\hline \multicolumn{1}{|c|}{ Former DET set } & \multicolumn{1}{c|}{ Former HOR set } \\
\hline School 8 (Above Demographic Average) & School 7 (Above Demographic Average) \\
\hline 1 moderate pedagogy & 2 strong pedagogies \\
2 weak pedagogies & 1 moderate pedagogy \\
\hline School 3 (Above Demographic Average) & School 6 (Above Demographic Average) \\
\hline $\begin{array}{l}\text { 2 moderate pedagogies } \\
2 \text { weak pedagogies }\end{array}$ & $\begin{array}{l}\text { strong pedagogy } \\
\text { 1 teacher's lesson not recorded }\end{array}$ \\
\hline School E (Below Average) & School D (Below Average) \\
\hline 2 weak pedagogies & 2 weak pedagogies \\
1 teacher's lesson not recorded & \\
\hline
\end{tabular}

The table shows that within the former DET set, there were no teachers who demonstrated a strong pedagogy according to the measures for strong pedagogic features. It is important to mention that the teachers who demonstrated a moderate pedagogy in the former DET set all displayed a weak cognitive demand by working within a number range that was limited to one and two digit numbers. This means that all of these teachers were not teaching at the expected three digit number range that is prescribed in the Grade 3 CAPS curriculum. These lessons were recorded in the second term of the year, by which time Grade 3 learners should be working with three digit numbers. Some of these teachers did work at an appropriate pace, and made evaluation criteria explicit and in some cases presented coherent lessons, but the cognitive demand of lessons was below the grade level expectations. Carnoy et al. (2012) gives some insights into the implications of teaching at inappropriate levels of cognitive demand. Pitching lessons at appropriate levels of cognitive demand requires teachers to have a strong hold on mathematics content knowledge. Teaching mathematics lessons at appropriate levels of cognitive demand enables learners to grasp the concepts being taught as well as the connections between concepts that lead to a deeper understanding of the subject. In contrast to the teachers at the former DET schools, the former HOR set had three teachers who demonstrated strong pedagogies. These teachers all displayed strong pedagogic features as discussed above. These teachers were confident throughout their lessons; they taught with ease and were fluent in the mathematics they taught.

When linking the pedagogic ratings of the teachers in the table above to the performance of the schools, the analysis suggests that classroom practices and particular pedagogic strategies as measured through strong pedagogic features have an impact on learner performance at the level of the classroom and at the level of the school. All four teachers observed at both below average performing schools demonstrated weak pedagogies. This suggests that the weak pedagogies in the classroom were consistent with the weak or the below average school performance. In contrast, the schools performing above average had teachers who demonstrated strong, moderate and weak pedagogies. This again suggests that the cumulative 
effect of strong and moderate classroom pedagogies were reflected in the above average school performance.

Another important observation stems from the lessons taught by all the teachers in School 3 and School 7 (both schools that are performing above demographic average). Within both schools, the teachers taught the same lessons from what appeared to be the same lesson plans. In School 7 the focus of all three lessons were on fractions and even though there was some difference in the way the topic was put across to learners, there was a clear focus on fractions in oral and written tasks. In School 3 the topic of place value was taught in the exact same manner to groups on the mat in all four lessons observed. Such uniformity in lessons suggests a strong focus on teachers planning and preparing together for numeracy lessons in these two schools. In contrast to this, the two teachers at School E taught different topics in their lessons on the same day.

Taylor, Muller \& Vinjevold (2002) added lesson planning to their list of educational factors expected to affect learning. This suggests that when lessons are planned on a continuous basis and the lesson plan mirrors effective pedagogical strategies as well as covers the necessary content according to curriculum specifications; then there is greater potential for more effective lessons in classrooms. For schools with teachers who have weak, moderate and strong pedagogies; collaborative lesson planning could be an effective tool to improve school performance if all teachers begin to adopt the features of strong pedagogies. During lesson planning sessions, these teachers could share pedagogic methods and those with weak pedagogic strategies could learn from those teachers with moderate or strong pedagogical strategies. In the sample of schools, School 7 and School 3 stands out as examples where despite the weak and moderate pedagogies at the Grade 3 level, these schools still perform above demographic expectation. These results could stem from a myriad of factors that produce positive results. However, the example of teachers planning lessons together and teaching the same lesson accordingly in two higher performing SPADE schools suggest that when teachers plan lessons together (which mirrors effective pedagogic strategies), there is greater opportunity for uniformity, support for teachers with weaker pedagogies and potentially higher learner and school achievement.

\section{Conclusion}

Research studies often homogenise schools that are situated in lower-income communities and that are labelled as poor. They are predominantly homogenised in terms of their performance, and in terms of their capacity to perform better than what is expected of them. A project such as SPADE, which studies lower and higher performing schools in lower-income communities comparatively, breaks from this tradition of homogenising. The project highlight schools that are performing better amidst the challenges and difficulties of their location; it also highlights the strengths within these schools that allow for such performance. 
This specific analysis within the wider SPADE project foregrounds certain pedagogic strategies as both available to learners at schools in lower-income communities and, it shows how these strategies are spread across schools of differential performance. The analysis identifies certain kinds of pace, sequence and coherence of the lesson, cognitive demand and nature of feedback as pedagogic strategies that could impact positively or negatively on school performance. It highlights that schools that are situated in lower-income communities and that are labelled 'poor' have teachers with not only weak pedagogies, but strong and moderate pedagogies as well. This means that not all pedagogic practice in poor schools are the same; there is variation between and within some of these schools. Furthermore, it suggests that pedagogy is linked to performance and that when certain pedagogic strategies form a part of lessons in a relational manner; it can have an impact on learner and school results. The paper also suggests that schools in these contexts can perform well in the event of having only weak and moderate pedagogies (such as School 8 and School 3 in the sample). However, other aspects of pedagogy such as uniformity in curriculum planning can strengthen performance.

Pedagogy should be included as a factor that potentially relates to higher school performance. It is hoped that the measure of pedagogy used within this analysis can be productively utilised in further studies in other poor school contexts. This will potentially allow for great insights or clarity on the relationship between pedagogic strategies in the classroom and school performance.

\section{Acknowledgement}

This paper is based on work conducted within the SPADE research project, which is sponsored by the Department of Higher Education and Training and the Department of Basic Education through the European Union Primary Education Sector Policy Support Program. Any opinions, findings, conclusions or recommendations expressed in this material are those of the author and do not necessarily reflect the views of the sponsors. In writing this paper, the author has been supported and guided by $\mathrm{Dr}$ Ursula Hoadley and Jaamia Galant.

\section{Endnote}

1. Performance 'above demographic expectation' for former HOR schools was measured against the average performance of former HOR schools, and performance 'above demographic expectation' for former DET schools was measured against the average performance of former DET schools.

\section{References}

Anghileri, J. 2006. Teaching number sense ( $2^{\text {nd }}$ edition). London: Continuum.

Carnoy, M. \& Chisholm, L. 2011. Towards understanding student academic performance in South Africa: A pilot study of Grade 6 Mathematics lessons in South Africa. Report prepared for the Spencer Foundation. Pretoria: HSRC. 
Carnoy, M., Chisholm, L. \& Chilisa, B. 2012. The low achievement trap: Comparing schooling in Botswana and South Africa. Cape Town: The Low Achievement Trap.

Ensor, P., Hoadley, U., Jacklin, H., Kühne, C., Schmitt, E., Lombard, A. \& Van den HeuvelPanhuizen. 2009. Specialising pedagogic time and text in Foundation Phase mathematics classrooms. Journal of Education 47:4-30.

Fuson, K. 1992. Research on whole number addition and subtraction. In Gouws, D. (Ed.), Handbook of research on mathematics teaching and learning. New York: Macmillan; pp. 243-275.

Hoadley, U. 2012. What do we know about teaching and learning in South African primary school? Education as Change 16(2):187-202.

Hoadley, U. 2007. The reproduction of social class inequalities through mathematics pedagogies in South African primary schools. Journal of Curriculum Studies 39(6):679-706.

Morais, A. \& Pires, D. 2002. The what and the how of teaching and learning: Going deeper into the sociological analysis intervention. Presentation to the Second international Basil Bernstein Symposium: Knowledge, pedagogy and society. University of Cape Town.

Muller, J. 2006. Differentiation and Progression in the Curriculum. In Young, M. \& Gamble, J. (Eds.), Knowledge, Curriculum and Qualifications for South African Further Education. Human Sciences Research Council: Cape Town; pp. 66-86.

Reeves, C. \& Muller, J. 2005. Picking up the pace: variation in the structure and organisation of learning school mathematics. Journal of Education 37:103-130.

Reeves, C. \& Mc Auliffe, S. 2012. Is curricular incoherence slowing down the pace of school mathematics in South Africa? A methodology for assessing coherence in the implemented curriculum and some implications for teacher education. Journal of Education 53:9-36.

Reitzug, U. \& Patterson, J. 1998. “I'm not going to lose you!” Empowerment through caring in an urban principal's practice with students. Urban Education 33(2):150-181.

Taylor, N. 2008. What's wrong with South African schools? Johannesburg: JET Education Services.

Taylor, N. 2007. Equity, efficiency and the development of South African schools. In T. Townsend (Ed.), International Handbook of School Effectiveness and Improvement. Springer International Handbooks of Education 17. Dordrecht: Springer.

Taylor, N., Muller, J. \& Vinjevold, P. 2003. Getting Schools Working: Research and Systemic School Reform in South Africa. South Africa: Getting Schools Working.

Stylianou, D. 2010. Teachers' conceptions of representation in middle school Mathematics. Journal of Mathematics Teacher Education 13: 325-343.

Venkat, H. \& Naidoo, D. 2012. Analyzing coherence for conceptual learning in a Grade 2 numeracy lesson. Education as Change 16(1):21-33. 